\title{
Enseñar literatura, tal vez soñar
}

\section{Manuel Abril}

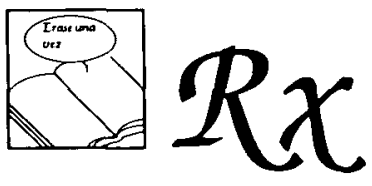

Se bace aqui una reflexión que, partiendo del sentido (la literatura no se enseña, se contagia), adopta un enfoque funcional y comunicativo. Frente a una literatura como objeto se opta por una literatura como medio. Frente a la memoria, la competencia. Enseñar a usar la lengua y la literatura más que enseñar lengua y literatura:

\section{INTRODUCCION. MARCO CIENTIFICO-CONCEPTUAL}

Debo empezar explicando el título propuesto. Y debo hacerlo para aclarar la doble connotación que de él se desprende: porque tal vez enseñar Literatura es un sueño utópico, en lo que atañe al profesor; y porque tal vez sirva para enseñar a soñar, y esto correspondería más al efecto en los alumnos.

Y empiezo también por dejar bien sentados los objetivos específicos en los que fundamento estas reflexiones, objetivos que conviene tener bien presentes en todas las actividades didácticas de la enseñanza-aprendizaje de la Literatura: ampliar y actualizar la formación del profesorado en técnicas de reconocimiento de los diversos componentes didácticos, en técnicas de trabajo intelectual, motivación, animación y dinamización de grupos, en técnicas de análisis, observación de experiencias y otros objetivos que, seguramente, puedan desprenderse del propio desarrollo que sigue.

«La Literatura no se enseña, se contagia». Es una reflexión de Luis Landero que aparecía en una entrevista que le hacían en un periódico, recientemente. Y si tiene razón, como parece tenerla, poco más podrá decirse al respecto, como no sea intentar el contagio; pero eso no es tan seguro. Por esta razón hemos de dejar bien sentadas una serie de cuestiones para esta intención.

Imaginemos por un momento que estamos de nuevo en el año 1974 y que un sesudo catedrático nos invita a contestar una encuesta sobre Literatura y sus implicaciones. Probablemente nuestras respuestas no diferirían en mucho de las que por aquel entonces daban toda una serie de prestigiosos personajes a las cuestiones planteadas por Fernando Lázaro Carreter (1974). Eran éstas:

«1) Asistimos en nuestros días a una auténtica crisis en la enseñanza de la 
Literatura, que es mirada con recelo por una gran parte de la sociedad y del alumnado. ¿Cuáles son, a su juicio, las causas de esta crisis?

2) ¿Cree usted que el estudio de la Literatura debe mantenerse como parte de la educación de los españoles?

3) ¿Qué objetivos debe proponerse el profesor de Literatura en las enseñanzas media y universitaria?

4) ¿Piensa usted que tales objetivos pueden alcanzarse con los métodos actuales? En su caso, ¿qué métodos desearía ver implantados?

5) ¿Qué papel atribuiría usted al estudio de la Literatura del siglo en el conjunto de las enseñanzas literarias?»

(A los profesores a quienes entrevistó, en la última cuestión se cambiaba el siglo por el que se preguntaba. A los críticos y escritores las preguntas que se les formuló eran distintas.)

Es como si no hubiera pasado el tiempo. $\mathrm{O}$ apenas. Uno a veces tiene la impresión de que hay demasiados esfuerzos, y de que son poco eficaces las energías gastadas por los estudiosos investigadores, o por los que piensan demasiado, o por los profesores. En otras ocasiones, por el contrario, conviene pensar que todos los esfuerzos son pocos en esta intención didáctica: probablemente algunas de las respuestas a los interrogantes anteriores nos llevarían a reorientar decisivamente la tarea docente desde la inquietud y desde el convencimiento didáctico: el aprendizaje de habilidades y estrategias cognitivas -enseñar a aprender - exige concepciones y planteamientos, desde la necesaria coherencia, que dinamicen actividades sistemáticas en el docente para llegar a hacerse efectivas en el alumnado.

\section{FASES EN UNA UNIDAD DE APRENDIZAJE. PROPUESTAS}

Buena parte de las estrategias derivadas de la Psicología y de la Pedagogía son las que han de fundamentar una didáctica más coherente de la Lengua y la Literatura. En este sentido consideramos la recomendación general de una secuenciación en tres fases para las modalidades de comunicación, sea ésta oral, escrita o artística:

a) Perceptiva (en la que tienen cabida la lectura, la observación, la audición...)

b) Expresiva (ejecución personal, realización concreta).

c) Comunicativa (análisis final colectivo y evaluador).

Obviamente ha de aceptarse su coincidencia y su posible simultaneidad, puesto que no son gradaciones rígidas sino secuenciales.

V. Ferreres (1987), en cuanto a las fases necesarias para la realización de textos escritos, propone tres estadios:

a) Preparación remota (lecturas, obsevación...)

b) Preparación inmediata (ordenación, selección, delimitación...: ejecución).

c) Evaluación.

(Indudablemente, la enseñanza-aprendizaje de la Literatura posee sus propias diferencias frente a las de la expresión escrita, pero coinciden en ambas rasgos comunes.)

Consideremos una tercera propuesta: Mercedes Morilla (1982) sugiere un proceso que el alumno puede seguir en cada unidad de aprendizaje:

I. Fase de motivación inicial: fantasía, humor, poesía, imagen... 
II. Fase de experiencia lectora: comprensión, léxico, ampliación...

III. Fase de actividades de descubrimiento: oral, escrita, léxico, ortografía, desarrollo temático...

IV. Actividades de aplicación, extensión y evaluación.

Aplicado a la intención que nos ocupa y nos preocupa aquí, deben derivarse de cada fase las actividades que le son propias: de este modo, sistemática y coherentemente, se propiciará un aprendizaje denso desde los textos literarios, puesto que todas las actividades se concretan en exprimir el texto para enriquecer al receptor, en aprovechar el texto para dinamizar la enseñanza-aprendizaje de los alumnos.

María Hortensia Lacau (1966), abordando la didáctica de la lectura creadora, se planteaba sus experiencias con los alumnos como soluciones «intentando enseñarles a amar los libros, la lectura en profundidad, la posibilidad de expresarse», lo que de alguna forma nos lleva a dar respuestas a algunas cuestiones de las que el profesor Lázaro Carreter planteaba y hemos recogido antes. A fin de cuentas también creo, como debe creer la sensatez de cualquiera que enseña Literatura, que hemos de perseguir con esta didáctica dos objetivos prioritarios, y casi únicos, puesto que son lo suficientemente completos y complejos como para que engloben todos los demás objetivos que los profesores podamos plantearnos en la didáctica del hecho literario hacia el alumnado:

- enriquecer la sensibilidad (dotarles de posibilidades estéticas) y

- enriquecer los conocimientos (darles posibilidades reales de expresión de sí mismos).

\section{EL PROCESO DE ENSEÑANZA-APRENDIZAJE. INTERRELACIONES}

Desde hace tiempo se viene manteniendo como convicción didáctica que es empobrecedor para el alumnado y para el profesor (aunque con frecuencia más cómodo) limitar las actividades escolares a la consulta (y manejo y lectura y utilización) como instrumento de trabajo en el aula de un solo libro de texto: si el contrastar la información a través de diversas fuentes se reconoce como objetivo fundamental en la fase de análisis y de desarrollo de los temas de trabajo en diferentes áreas curriculares, hemos de convenir en que el material de consulta del que el alumnado ha de disponer debe ser diverso y multiforme, para que el propio trabajo investigador se diversifique en el contraste, la pluralidad, la disparidad de criterios a veces y la variedad que siempre, en principio, es más enriquecedora que la visión monolítica y definitiva e incuestionable. Lo mismo deberá entenderse de las lecturas propuestas o de las obras literarias sugeridas. El convencimiento de que la variedad de ofertas en las fuentes que se proponen al alumnado, para la enseñanza de la lengua y de la literatura, contribuirá decisivamente a diversificar los estímulos de creación y respuesta personal por la capacidad de transferencia a través de la comprensión, no debe bastarnos para acordar su utilización para el enriquecimiento cultural que supone la lectura como información, formación y entretenimiento: también lo debemos referir al trabajo concreto del aula en los niveles de Educación Primaria y Secundaria. Esto exige al propio docente romper con la comodidad en muchas ocasiones. Más comodidad aún cuando el propio texto utilizado recoge la programación de toda la actividad escolar para el docente, y ya no parece muy necesario detenerse en reprogramar los objetivos específicos y las actividades 


\section{4}

necesarias de cada aula concreta, porque ya el equipo técnico de las editoriales propone al inicio del texto o en documentos anexos una programación coherente, secuenciada, clara y uniforme; pero tan perfecta que asusta, y tan común que la hace ajena.

Y debemos añadir a lo anterior las distinciones que el profesor López Morales (1987) puntualiza: «El sistema comunicativo está estrechamente ligado a ciertas destrezas. En las llamadas "artes del lenguaje" se habla de ellas, pero es preciso verlas a la luz de la lingüística aplicada. Las destrezas hablar-entender corresponden, naturalmente, a la comunicación oral... Las destrezas paralelas escribirleer pertenecen a la comunicación escrita y copian (o tratan de copiar) las funciones del hablar-entender.. Todas están interrelacionadas; unas funcionan como antecedentes de las otras.»

En este sentido entendemos las imbricaciones e implicaciones de la tarea de enseñar lengua: debe ser enseñar a usar la lengua. Tal debería ser, sobre todo, el objetivo de esta enseñanza-aprendizaje. Y, no nos olvidemos, de la literatura: no sólo para usar ésta, sino por las derivaciones que con la lengua contrae: «El comentario de texto se considera la principal actividad por ser el ejercicio más completo de la didáctica literaria, ya que en él se combinan la comprensión y expresión, el análisis y la síntesis y la interpretación valorativa»: es una cita textrual de los Programas Renovados, MEC (1987).

Coincidente con lo anterior es la afirmación del profesor Lázaro Carreter (Montero, 1987): «Toda la enseñanza de la lengua y la literatura debe girar en torno a un texto», con el fin de mejorar y enriquecer la propia competencia comunicativa, es decir, para adquirir mayor libertad y seguridad en el uso de la lengua.

Pero busquemos otra opinión al respecto. Dámaso Alonso (1974), poco «sospechoso» de pretender efectos didácticos inmediatos - aunque sea en el fondo su ilusionada intención - en el prólogo a la obra antes comentada que Lázaro Carreter funde como vehículo de expresión de selectísimos profesores, escritores y críticos, afirma:

«Deseo más literatura en los planes de enseñanza y que sea preceptivo enseñarla, desde el principio, no como una retahila de nombres y fechas, sino principalmente por la lectura y comentario de las obras maestras, en ediciones acomodadas a los distintos niveles.»

(Los subrayados son nuestros.) Sus consideraciones no tienen desperdicio, y coincidimos plenamente en que debe ser el uso y disfrute de los textos el contenido y objetivo central de los que emanen todas las actividades que desde los primeros niveles de enseñanza hasta los niveles preuniversitarios deben seguirse.

En tal enseñanza-aprendizaje, la Literatura adquiere su prestigio y su consistencia, como fondo léxico, como núcleo morfosintáctico, como recurso de lo oral o como modelo de la ortografía al servicio de una comunicación más eficaz. O para soñar, que ya es bastante.

La iniciación al texto literario como manifestación de la funcionalidad de la lengua es una de las claves didácticas que ha de propiciar el aprovechamiendo y dinamización de actividades didácticas desde el texto: como Motivación inicial, y permanente; como Identificación, en la que tiene cabida la profundización de la historiografía acorde su análisis con el nivel de enseñanza; y como Reflexión («Análisis y reflexión de la propia lengua») para el desarrollo de la competencia comunicativa.

(Conviene no perder de vista la formulación que se diversifica desde la LOG- 
Figura 1

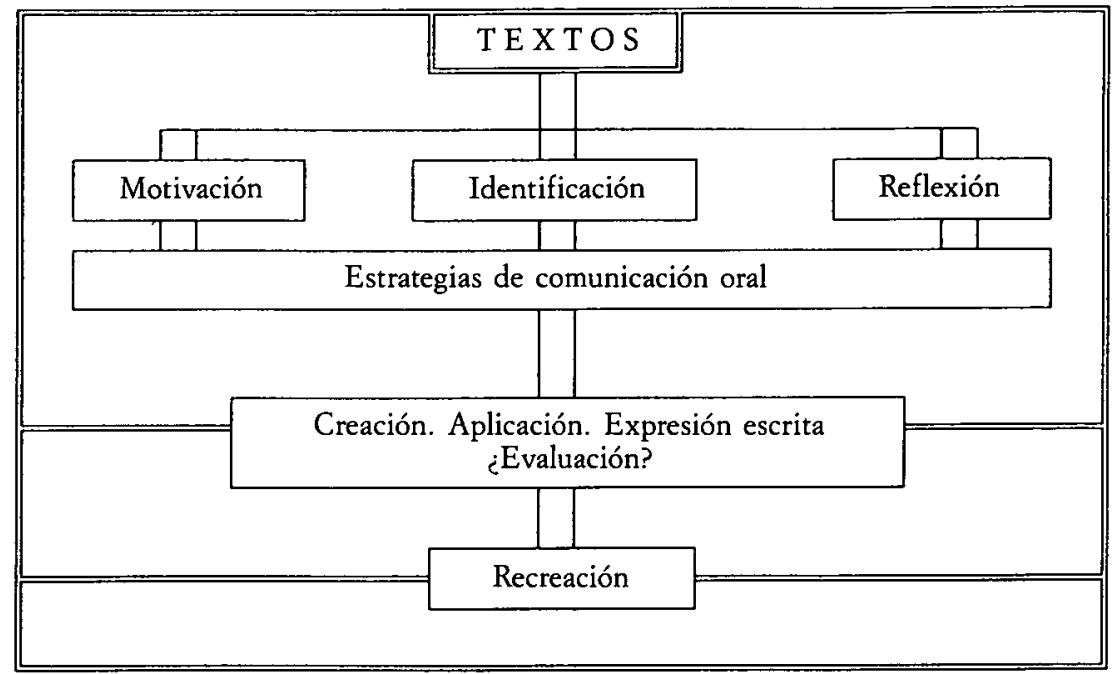

$\mathrm{SE}$ en los tres ámbitos que han de atenderse en los contenidos para el área de Lengua castellana y Literatura: Conceptos, Procedimientos y Actitudes.)

Debería considerarse, por tanto, y como primera conclusión, el aprendizaje de la literatura en los alumnos como un constante resolver problemas que contribuyese a afinarlos, a hacerlos más perspicaces, a empezar la búsqueda y conocimiento de sus propios recursos; en una palabra, a capacitarlos, dándoles herramientas probadas de raciocinio, sensibilidad, personalidad y fantasía: la propia creatividad (lingüística y personal) se posibilitará más armónica y consecuentemente. Así la Literatura servirá también para incorporar aprendizajes lingüísticos.

\section{ENSEÑAR A APRENDER: RELACIONES INTERDISCIPLINARES}

El profesor de Literatura (Infantil, Juvenil, Literatura en general), para poder «contagiar» a los alumnos en esta disciplina, debe ser portador de un decidido entusiasmo para poderlos acercar a la comprensión honda y crítica de la vivencia literaria. Inicialmente. Seleccionando los rasgos que la LOGSE propone, deberá ser: conocedor; orientador; dotado de buen gusto (sensibilidad); tener formación filológica; y no descuidar la faceta de la investigación. Además, ha de favorecer los aspectos creativos de sus alumnos, para lo cual él mismo deberá realizar y utilizar estrategias necesarias para crear las condiciones más favorables para el buen desarrollo de la creatividad (Alonso, 1974). Y todo esto, con el convencimiento de que además de conservar lo convencional y tradicional, de luchar con las presiones externas e internas, ha de superar el recelo de las actividades escolares que no parecen producir resultados tangibles y rápidos (Rogers, 1962).

Los textos, cualesquiera que sean sus caracteres, pueden constituir muy a menudo lo que algunos han denominado «una lección de cosas». Manuel Seco (1966) afirma: «La misma literatura es una eficaz colaboradora en la tarea de dar una cultura general. Porque además de ideas y sentimientos, la obra literaria puede encerrar toda suerte de datos históricos, geográficos, científicos, folclóricos...»

Pero conviene actuar con precaución en esto. Juan Cervera (1988) advierte: «Si a partir de un determinado cuento pretendemos enseñar unas cuantas no- 
ciones de lengua, seguidas de otras tantas de cálculo, más otras del área de social, para completar el muestrario con otras de moral o de religión, lo que estamos haciendo es desprestigiar el propio cuento que indudablemente no contiene nada de eso más que de una forma secundaria. Entonces se cae en un torpe remedo de la enseñanza ocasional que además incurre en el contrasentido de quererse presentar como sistematizada. Por añadidura, así sólo se valora la corteza del cuento.»

Ciertamente, al igual que sucede con las interrelaciones lúdicas que deriven de los textos, sobre todo los que se proponen como iniciación a la literatura, el placer del juego creador del lenguaje, o el arrancar sonrisas, o cualquier otro fin que se persiga, pueden ser suficientes efectos si se consiguen. Pero debemos ser conscientes, se ha de partir de una fina formulación de objetivos en esta enseñanza; en esta intención recogemos tres consideraciones coincidentes:

- «El juego con la palabra, y con el lenguaje en general, es una de las actividades naturales del niño.» (Cervera, 1988).

- «Hora es ya de abandonar para siempre aquella didáctica del idioma que operaba sobre la palabra aislada o la frase alejada de toda vivencia.» (Medina, 1989). $Y$ esto, consecuentemente, debe referirse a las enseñanzas-aprendizajes de los aspectos oral, ortográfico, léxico, morfosintáctico, lector... y literario. $\mathrm{O}$ quizá, como antes señalaba, es que todo sea, en el fondo, un único aspecto: el del aprendizaje de la lengua desde los textos, el de la enseñanza de la literatura desde la lengua.

- «Toda enseñanza de la lengua y la literatura deben girar en torno a un texto", la propuesta de Lázaro Carreter que cité antes.

Si todo juego literario, toda didáctica y toda enseñanza deben girar en torno a un texto, es obvio que la elección y propuesta de modelos válidos ha de superar la primera selección a la que debemos someter todo texto: la de la ilusión. $\mathrm{Y}$ aun cuando aquí no nos corresponde abordar esta cuestión, hemos de tener presente que esta responsabilidad de la selección de los textos ha de ser otro requisito que el profesor de literatura debe considerar.

En esta «fina formulación de objetivos» en esta enseñanza, a la que antes aludía, la interdisciplinariedad es donde cobra su importancia:

«En la primera etapa de EGB (ciclos inicial y medio), la existencia de un profesor de grado, responsable único de la enseñanza en todas sus vertientes, obliga al docente interesado en un planteamiento globalizado del conocimiento a la búsqueda de un artificio metodológico que permita su presentación al alumnado» (Parra, 1989): nuestro artificio metodológico son textos motivadores que se armonicen en un proyecto interdisciplinar, si así se quiere, el cual se integre en el currículo escolar del Proyecto Curricular de Centros: los diseños de unidades didácticas que se vienen gestando pueden generarse desde textos que unifiquen objetivos, contenidos y actividades de las áreas de Lengua castellana y Literatura, Ciencias Sociales, Ciencias Naturales, Matemáticas y Educación Artística (subáreas de Plástica, Música y Expresión Corporal) —no se modifican tales consideraciones en cuanto al profesor «responsable único» ni en lo que afecta a la estructuración de áreas, desde la reorganización de la LOGSE-. Esto requiere nuevos planteamientos: «Los equipos docentes tienen la responsabilidad de adecuar las prescripciones y orientaciones del DCB a su contexto específico. Para la realización de esta tarea son necesarias, fundamentalmente, dos cosas:

- que los equipos docentes sepan trabajar como tales en la consecución de metas colectivas, para lo que deberán organizarse y requerir los apoyos necesarios, $\mathrm{y}$

- saber identificar y obtener el conocimiento y los datos necesarios que les hagan falta para realizar esta contextualización, para lo cual deberán también proveerse de los apoyos precisos.» (La Reforma Educativa, 1990). Son las propuestas 
«oficiales» que anticipan los prerrequisitos para el caminar de la Reforma: obliga a la coordinación del profesorado, de las diversas áreas; integra intenciones y atenciones; requiere abandonar dominios personales y áreas (físicas y de conocimiento) exclusivos. Invita a caminar juntos. Y esto no sólo es bueno, es necesario. Y vital.

Idéntica consideración se mantiene desde varios frentes:

«De todo lo anterior, parece deducirse que los sistemas educativos de las sociedades avanzadas, entre otras cualidades, exigen a los profesores

- conocimientos teóricos acerca de la disciplina que imparten que les permitan una adecuada selección de contenidos, cativa,

- conocimientos pedagógicos que les permitan organizar la actividad edu-

- capacidad de trabajo en equipo,

- capacidad de elaboración de materiales de clase.» (González, 1991)

Con la intención de unificar el encadenamiento de citas, reflexiones y propuestas hasta ahora apuntados, debemos coincidir en esta división que mantenemos: se trata de proponer los textos como núcleos que originen actividades interdisciplinares, sobre todo en los primeros niveles de la enseñanza, cuya motivación es servir de acercamiento de los pequeños lectores al texto literario, escrito y oral, y como iniciación para las futuras actividades propuestas a los más maduros, para quienes los textos han de constituirse y proponerse como modelos válidos en los que la lengua sirva de instrumento de comprensión; y textos como sugerencias de vivencias, formulación de posturas, síntesis de visiones del mundo y ofertas de enriquecimiento personal, cultural y lingüístico. Así la Literatura conseguirá los efectos de formación e información, objetivos que anticipaba al introducir estas reflexiones y propuestas.

En resumen, han de realizarse en la enseñanza de la Literatura cuatro tareas independientes: investigar, organizar, crear y comunicar (Darrow, 1966): Tarea compleja pero apasionante por su propia significación, y decisiva por los resultados que ha de proporcionar.

\section{CONCLUSION}

La Literatura puede ser aceptada desde una doble consideración: como modelo de transferencia (incidencia indirecta) o como un fin en sí mismo. Decantarse por una u otra en nada afectaría a su identidad: el arte es siempre útil de alguna manera: educa la sensibilidad - para algunos la base fundamental de la educación-y suele ofrecer en su mundo referencial estilos de vida y normas de conducta. Las diversas concepciones de su naturaleza y fines, como han ido primando en diferentes épocas, no han hecho sino ir completando su significación: noticia (memoria); conocimiento (testimonio); evasión (recreación); contemplación (vivencia); catarsis... Aun cuando no nazca con ninguna de esas finalidades, la capacidad de transferencia que fundamenta su singularidad puede hacerse efectiva en los tres ámbitos en que la hemos considerado: formación, información y entretenimiento... [«... y ayudaremos así a formar alumnos más creativos, propiciaremos también usos más creativos y dinámicos del lenguaje y transformaremos a nuestros estudiantes de consumidores pasivos a bacedores constructivos» (Abril, 1991)]: mantengo las mismas convicciones con idéntico convencimiento. ... Pero ojalá que estas reflexiones fueran inicio, mejor que conclusión: de planteamientos didácticos para que llegue a ser efectivo el hecho literario en el alumnado, desde el contexto y desde la vivencia, para que posibilite futuras aproximaciones a lo intelectual y cultural en lo literario: si creamos la necesidad de leer en los alumnos, habremos cubierto sobradamente los objetivos que deben orientar toda actividad escolar y, por supuesto, toda didáctica en lo que 
intentamos enseñar literatura y creemos en cuanto la define y la justifica: en la firmeza de su enormidad a través de la incorporación de procedimientos y de la reconstrucción de actitudes; en la capacidad de transferencia de los modelos lingüísticos del hecho literario.

$\mathrm{O}$, simplemente, en su inestimable aportación a la fantasía y a la ilusión.

\section{Sugerencias de lectura}

Agüera, I. (1990). Curso de creatividad y lenguaje, Madrid, Narcea.

Alvarez Méndez.J. M. (Comp.) (1987). Teoría lingǘstica y enseñanza de la lengua, Madrid, Akal. Cox, B. (1990). «English teaching: the need for reform», en English Today, 21, January, pp. 20-28. Franco. A. (1988). Escribir: un juego literario, Madrid, Alhambra, 1. ${ }^{a}$ ed.

Valle A., F. (1991). Psicolingüistica, Madrid, Morata.

WELLS, G. (1988). Aprender a leer y a escribir, Barcelona, Laia.

\section{Referencias}

A $\mathrm{BRIL}$, M. (1991). Comunicacions, II Simposi Internacional de didáctica de la llengua i la literatura, Tarragona, Escola de Mestres, pp. 7-12.

Alonso, D. (1974). Literatura y Educación, op. cit. p. 17.

Cervera, J. (1988). «Lenguaje escrito y lúdico», en Medina, A. y García P., J. (Dirs.) (1988). Didáctica de la Lengua y la Literatura, Anaya, Madrid, pp. 257-277.

Cervera, J. (1988). La literatura infantil en la educación básica, Cincel-Kapelusz, Madrid, p. 38.

Citado por Montero P. J. (1989). Sobre Didáctica de la Lengua y la Literatura (Homenaje a Arturo Medina), Publicaciones Pablo Montesino, Madrid, «Preliminar», p. XII.

Darrow Allen (1966). Actividades para el aprendizaje creador, Paidós, Buenos Aires.

Dirección General de Ordenación Educativa, Consejería de Educación, Cultura y Deportes del Gobierno de Canarias (Mayo, 1990): La Reforma educativa. Documento Sintesis, Canarias, p. 12.

FerReres. V. (1987). Enseñanza y valoración de la composición escrita, Cincel-Kapelusz, Madrid, p. 37.

GonZñLEZ, L. «La formación permanente del profesorado de Lengua y Literatura: Modelos teóricos y actuación del asesor», en C.L.E E., 1991, 9, 45-56.

JoNes, T. P. (1973). El educador y la creatividad del niño, Narcea, Madrid.

Lacau, M. ${ }^{\circ}$ H. (1966). Didáctica de la lectura creadora, Kapelusz, Buenos Aires.

Lazıro, C. F. (1974). Literatura y educación, Castalia, Madrid, p. 21.

López M. H. (1987). Enseñanza de la lengua materna (Lingǘstica para maestros del español), Playor, Madrid, pp. 28-29.

M. E. C. (1987). Programas Renovados de la EGB. Ciclo Superior. 6. $7^{\circ} .^{\circ}$ y $80^{\circ}$ Cursos, Escuela Espanola, Madrid, 4. ${ }^{\mathrm{a}} \mathrm{ed}$.

Medins. A. Cit. por Montero P. J. en Sobre didáctica de la Lengua y la Literatura. (Homenaje a Arturo Medina), Publicaciones Pablo Montesino, Madrid, 1989, Preliminar, p. XII.

Morillı. M., y otras (1982). «Bases para una didáctica del lenguaje», en Aprendizaje de la Lengua en el Ciclo Medio, Narcea, Madrid, p. 55.

PARR O. J. M.a. «Una propuesta de estudio interdisciplinar de las áreas Social y Lingǘstica», en Sobre didáctica de la Lengua y la Literatura, op. cit. pp. 71-93.

Rogers, C. R. (1962). «Toward a Theory of Creativity», en Parnes, S. J., y Harding, H. F. (Dirs.): A Sure Book for Creative Thinking, Nueva York, pp. 63-72.

SECO, M. (1966). Metodologia y didáctica de la lengua y la literatura españolas, Publicaciones de la Dirección General de Enseñanza Media, Madrid, p. 41. 


\section{Enseñar literatura, tal vez soñar Manuel Abril \\ CL\&E, 1993, 18, pp. 91-99}

Resumen: Enriquecer la sensibilidad y los conocimientos son dos objetivos fundamentales, y dos consecuencias a la vez, que puede favorecer la enseñanza literaria.

Se propone un modelo de transferencia de la Literatura significando las incidencias que se relacionan con la comunicación oral, la lectoescritura, la reflexión sobre el uso de la lengua y la lectura y escritura creadoras: La Didáctica de la Literatura pretende dinamizar desde los textos las actividades lingüísticas: la interdisciplinariedad se propicia desde los elementos motivadores, creativos y reflexivos que de ellos se desprenden. Aprovecharlos significa creer en su potencialidad y en su vitalidad para dinamizar actividades interrelacionadas.

La experiencia - la vivencia del hecho literario- debe implicar el entusiasmo del docente para que llegue a hacerse efectivo en el alumnado. Así transformaremos a nuesros alumnos de consumidores pasivos de literatura a creadores activos $y$ recreadores de cuanto en los textos (propuestos o incorporados) puedan descubrir.

Datos sobre los autores: Manuel Abril es profesor de Didáctica de la Lengua y la Literatura en la Escuela Universitaria de Formación del Profesorado de la Universidad de La Laguna.

Un análisis de la Expresión escrita en escolares es su investigación más reciente. Actualmente su línea de investigación se orienta por un área sugeridora: Lectura y escritura creadoras, Tesis doctoral en curso.

Dirección: Manuel Abril Villalba. E. U. de Formación del Profesorado de E.G.B. C/ Heraclio Sánchez, 37. 38204 La Laguna. Tenerife.

(C) De todos los artículos deberá solicitarse por escrito autorización de CL\&E y de los autores para el uso en forma de facsímil, fotocopia o cualquier otro medio de reproducción impresa. CL\&E se reserva el derecho de interponer las acciones legales necesarias en aquellos casos en que se contravenga la ley de derechos de autor.
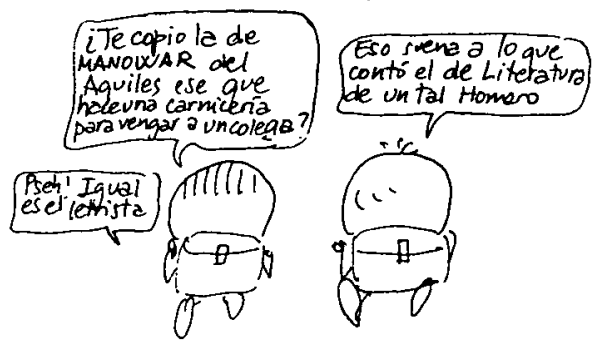